\title{
Diffusion Decay Coefficient for Chloride Ions of Concrete Containing Mineral Admixtures
}

\author{
Jae-Im Park, ${ }^{1}$ Kwang-Myong Lee, ${ }^{2}$ Soon-Oh Kwon, ${ }^{3}$ Su-Ho Bae, ${ }^{3}$ \\ Sang-Hwa Jung, ${ }^{4}$ and Sung-Won Yoo ${ }^{5}$ \\ ${ }^{1}$ Metropolitan Transit System Research Division, Korea Railroad Research Institute, Uiwang 16105, Republic of Korea \\ ${ }^{2}$ Department of Civil and Environmental Engineering, Sungkyunkwan University, Suwon 16419, Republic of Korea \\ ${ }^{3}$ Department of Civil Engineering, Andong National University, Andong 36729, Republic of Korea \\ ${ }^{4}$ Department of Preceding Research, Korea Conformity Laboratories, Seoul 08503, Republic of Korea \\ ${ }^{5}$ Department of Civil and Environmental Engineering, Woosuk University, Jincheon 27841, Republic of Korea
}

Correspondence should be addressed to Kwang-Myong Lee; leekm79@skku.edu

Received 4 March 2016; Accepted 21 April 2016

Academic Editor: Yuyin Wang

Copyright (C) 2016 Jae-Im Park et al. This is an open access article distributed under the Creative Commons Attribution License, which permits unrestricted use, distribution, and reproduction in any medium, provided the original work is properly cited.

\begin{abstract}
The diffusion coefficient for chloride ions and the diffusion decay coefficient for chloride ions are essential variables for a service life evaluation of concrete structures. They are influenced by water-binder ratio, exposure condition, curing temperature, cement type, and the type and use of mineral admixture. Mineral admixtures such as ground granulated blast furnace slag, fly ash, and silica fume have been increasingly used to improve resistance against chloride ions penetration in concrete structures built in an offshore environment. However, there is not enough measured data to identify the statistical properties of diffusion decay coefficient for chloride ions in concrete using mineral admixtures. This paper is aimed at evaluating the diffusion decay coefficient for chloride ions of concrete using ordinary Portland cement or blended cement. NT BUILD 492 method, an electrophoresis experiment, was used to measure the diffusion coefficient for chloride ions with ages. It was revealed from the test results that the diffusion decay coefficient for chloride ions was significantly influenced by W/B and the replacement ratio of mineral admixtures.
\end{abstract}

\section{Introduction}

With the deepening understanding of durability performance for concrete structures exposed to chloride attack, interest has increased in enhancing their durability and service life. In order to ensure the durability of concrete structures, many countries have developed durability design methods, including the DuraCrete design method, Life-365 Service Life Prediction Model, and fib model code [1-4], based on previous research. Due to this trend, probability-based durability design techniques have been developed which predict the service life of concrete structures by considering the statistical data of the variables related to the penetration analysis for chloride ions. In recent years, a probability-based durability design has been applied to a number of important concrete structures in many countries where a high degree of safety, durability, and service life have been of special importance $[4,5]$.
The major factors in predicting the service life of concrete structures exposed to chloride environment are chloride content at the surface of the concrete, critical chloride content for corrosion of reinforcing steel, the diffusion coefficient, and diffusion decay coefficient of chloride ions. In particular, the diffusion coefficient and diffusion decay coefficient for chloride ions in concrete are essential for determining the service life of RC structures exposed to chloride environment $[6,7]$. General values for selecting a proper diffusion decay coefficient are given in the literature and show observed diffusion decay coefficient for various types of concrete based on various binder systems exposed to the tidal and splash zones of marine environment $[1,3,8]$. However, previous studies have shown that the diffusion of chloride ions through concrete is a complex and time-dependent phenomenon controlled by numerous interdependent parameters [9-12].

The major factors influencing the diffusion of chloride ions in concrete include W/B (water-binder ratio), 
TABLE 1: Physical properties and chemical composition of cement and mineral admixtures.

\begin{tabular}{lccccccccc}
\hline \multirow{2}{*}{ Type of binder } & \multicolumn{3}{c}{ Physical properties } & \multicolumn{5}{c}{ Chemical composition } \\
& Specific gravity & Blaine $\left(\mathrm{cm}^{2} / \mathrm{g}\right)$ & $\mathrm{SiO}_{2}(\%)$ & $\mathrm{Al}_{2} \mathrm{O}_{3}(\%)$ & $\mathrm{Fe}_{2} \mathrm{O}_{3}(\%)$ & $\mathrm{CaO}(\%)$ & $\mathrm{MgO}_{(\%)}$ & $\mathrm{SO}_{3}(\%)$ & $\mathrm{R}_{2} \mathrm{O}(\%)$ \\
\hline OPC & 3.15 & 3,410 & 21.1 & 4.6 & 3.5 & 61.8 & 3.2 & 2.1 \\
GGBFS & 2.89 & 4,893 & 34.1 & 16.1 & 0.4 & 42.3 & 4.1 & 2.5 \\
FA & 2.23 & 3,750 & 56.5 & 27.1 & 4.4 & 3.8 & 0.8 & 0.2 & 1.3 \\
\hline
\end{tabular}

TABLE 2: Physical properties of fine and coarse aggregates.

\begin{tabular}{lccccc}
\hline Type & Specific gravity & Absorption $(\%)$ & Unit mass $\left(\mathrm{kg} / \mathrm{m}^{3}\right)$ & Amount of passing 0.08 mm sieve $(\%)$ & Fineness modulus \\
\hline Fine aggregate & 2.58 & 1.47 & 1,597 & 2.2 & 2.43 \\
Coarse aggregate & 2.65 & 0.58 & 1,648 & - & 7.27 \\
\hline
\end{tabular}

the temperature of the surrounding environment, exposure condition, curing temperature, cement type, and the use of mineral admixtures such as fly ash (FA), ground granulated blast furnace slag (GGBFS), and silica fume (SF). The use of blended cement has recently increased to improve resistance against chloride ions penetration in concrete structures built in a marine environment $[6,7,13,14]$. While estimates of the diffusion coefficient for chloride ions have been made for use in the design of durable concrete structures, overseas data are mainly used due to the lack of domestically measured data for the identification of statistical properties. Consequently, it is necessary to accumulate measured data on the diffusion coefficient for chloride ions and the diffusion decay coefficient for chloride ions to ensure the reliable durability design of concrete structures exposed to marine environment $[10,14,15]$.

In this study, concrete using ordinary Portland cement (OPC) and binary blended cement (BBC) was produced to evaluate the diffusion decay coefficient for chloride ions of concrete. An electrophoresis experiment, based on the NT BUILD 492 method [16], was employed to measure the diffusion coefficients for chloride ions of concrete at 28, 91, 182, 273, and 365 days. Empirical formula was proposed to predict the diffusion decay coefficient for chloride ions in concrete with OPC or $\mathrm{BBC}$, considering $\mathrm{W} / \mathrm{B}$ and the replacement ratio of mineral admixtures such as GGBFS and FA. The predictions by the proposed empirical formulas agreed well with the measurements.

\section{Experimental Work}

2.1. Materials. OPC, GGBFS, and FA were used in the production of the two types of blended cement $(\mathrm{OPC}+$ GGBFS, OPC + FA). The physical properties and chemical compositions of OPC and mineral admixtures are summarized in Table 1 . River sand and crushed rocks with a maximum size of $25 \mathrm{~mm}$ were utilized as the fine aggregates and coarse aggregates, respectively, and their physical properties are shown in Table 2. In order to ensure the workability of the concrete mixture, air entraining (AE) agent and high-range water reducing agent of polycarbonic acid were used.
2.2. Mix Proportions and Specimen Preparation. Mineral admixtures, GGBFS and FA, were used to produce concrete using two types of binary blended cement and the replacement ratios of GGBFS were 20,40 , and $60 \%$ of the unit binder content, and the replacement ratios of FA were 10, 20, and $30 \%$ of the unit binder content, respectively $[17,18]$.

The mix proportions shown in Table 3 were determined to evaluate the diffusion coefficients for chloride ions in concrete with binary blended cement. Considering the workability of each W/B, the target slumps were $150 \pm 25 \mathrm{~mm}$ (W/B $=55 \%)$ and $180 \pm 25 \mathrm{~mm}(\mathrm{~W} / \mathrm{B}=35,45 \%)$, and the target air content was $5.0 \pm 1.5 \%$ for all mixtures. After concrete cylinders $(\varnothing 100 \times 200 \mathrm{~mm})$ were casted, they were demolded after 24 hours and cured in a water bath of $20 \pm 2^{\circ} \mathrm{C}$ until the test began.

2.3. Test Method of Diffusion Coefficient for Chloride Ions. The diffusion coefficients for chloride ions were measured to investigate the resistance of the concrete cylinders to chloride ions penetration. For this purpose, a migration setup was arranged to accelerate the movement of chloride ions under an external electrical field, as shown in Figure 1. A $50 \pm 2 \mathrm{~mm}$ thick slice was made from a concrete cylinder $(\varnothing 100 \times 200 \mathrm{~mm})$. The catholyte solution was $10 \% \mathrm{NaCl}$ by mass and the anolyte solution was $0.3 \mathrm{M} \mathrm{NaOH}$ in distilled water. To measure the penetration depth of chloride ions passing through the concrete slice, after applying a potential difference to the concrete specimen for a certain period of time, the specimen was split and $0.1 \mathrm{M} \mathrm{AgNO}_{3}$ solution was sprayed onto the surface of the split specimen.

The diffusion coefficient for chloride ions is estimated by

$$
D=\frac{R T}{z F E} \cdot \frac{x_{d}-\alpha \sqrt{x_{d}}}{t},
$$

where $E=(U-2) / L, \alpha=2 \sqrt{R T / z F E} \cdot \operatorname{erf}^{-1}\left(1-2 c_{d} / c_{0}\right), D$ is the diffusion coefficient for chloride ions, $z$ is the absolute value of ion valence, $F$ is Faraday's constant, $U$ is the absolute value of the applied voltage, $R$ is the gas constant, $T$ is the average value of the initial and final temperatures in the anolyte solution in kelvin, $L$ is the thickness of the specimen, $x_{d}$ is the average value of the penetration depth, $t$ is the 
TABLE 3: Mix proportions of concrete mixtures.

\begin{tabular}{|c|c|c|c|c|c|c|c|c|c|c|c|c|}
\hline \multirow{2}{*}{$\mathrm{W} / \mathrm{B}(\%)$} & \multirow{2}{*}{ Cement type } & \multirow{2}{*}{ Slump (mm) } & \multirow{2}{*}{ Air content $(\%)$} & \multirow{2}{*}{ S/a (\%) } & \multicolumn{7}{|c|}{ Unit mass $\left(\mathrm{kg} / \mathrm{m}^{3}\right)$} & \multirow{2}{*}{$\operatorname{HRWR}(\mathrm{B} \times \%)$} \\
\hline & & & & & Water & Cement & GGBFS & FA & SF & Fine agg. & Coarse agg. & \\
\hline \multirow{7}{*}{35} & OPC & 191 & 4.6 & \multirow{7}{*}{42} & 164.5 & 470 & 0 & 0 & 0 & 689 & 978 & 1.19 \\
\hline & GGBFS20 & 187 & 4.8 & & 164.5 & 376 & 94 & 0 & 0 & 687 & 974 & 1.22 \\
\hline & GGBFS40 & 194 & 4.7 & & 164.5 & 282 & 188 & 0 & 0 & 684 & 970 & 1.22 \\
\hline & GGBFS60 & 197 & 4.9 & & 164.5 & 188 & 282 & 0 & 0 & 681 & 966 & 1.06 \\
\hline & FA10 & 188 & 5.0 & & 164.5 & 423 & 0 & 47 & 0 & 683 & 968 & 1.10 \\
\hline & FA20 & 187 & 4.9 & & 164.5 & 376 & 0 & 94 & 0 & 676 & 958 & 1.06 \\
\hline & FA30 & 189 & 4.7 & & 164.5 & 329 & 0 & 141 & 0 & 669 & 948 & 1.02 \\
\hline \multirow{7}{*}{45} & OPC & 170 & 4.7 & \multirow{7}{*}{45} & 166.5 & 370 & 0 & 0 & 0 & 773 & 971 & 0.91 \\
\hline & GGBFS20 & 163 & 4.9 & & 166.5 & 296 & 74 & 0 & 0 & 771 & 968 & 0.90 \\
\hline & GGBFS40 & 169 & 5.0 & & 166.5 & 222 & 148 & 0 & 0 & 768 & 965 & 0.95 \\
\hline & GGBFS60 & 184 & 5.2 & & 166.5 & 148 & 222 & 0 & 0 & 766 & 962 & 0.85 \\
\hline & FA10 & 165 & 5.1 & & 166.5 & 333 & 0 & 37 & 0 & 768 & 964 & 1.00 \\
\hline & FA20 & 167 & 5.3 & & 166.5 & 296 & 0 & 74 & 0 & 762 & 957 & 0.95 \\
\hline & FA30 & 171 & 4.9 & & 166.5 & 259 & 0 & 111 & 0 & 756 & 950 & 0.90 \\
\hline \multirow{7}{*}{55} & OPC & 170 & 5.1 & \multirow{7}{*}{47} & 176 & 320 & 0 & 0 & 0 & 815 & 944 & 0.75 \\
\hline & GGBFS20 & 146 & 5.2 & & 176 & 256 & 64 & 0 & 0 & 813 & 942 & 0.70 \\
\hline & GGBFS40 & 159 & 5.0 & & 176 & 192 & 128 & 0 & 0 & 811 & 939 & 0.75 \\
\hline & GGBFS60 & 175 & 5.1 & & 176 & 128 & 192 & 0 & 0 & 809 & 937 & 0.75 \\
\hline & FA10 & 175 & 5.2 & & 176 & 288 & 0 & 32 & 0 & 810 & 939 & 0.85 \\
\hline & FA20 & 174 & 5.1 & & 176 & 256 & 0 & 64 & 0 & 805 & 933 & 0.80 \\
\hline & FA30 & 172 & 5.2 & & 176 & 224 & 0 & 96 & 0 & 800 & 927 & 0.75 \\
\hline
\end{tabular}


(a) Gum (silicon) sleeve
(e) Cathode solution
(b) Anode solution
(f) Cathode
(c) Anode
(g) Plastic shore
(d) Concrete test piece
(h) Plastic box

FIGURE 1: Details of migration test setup.

test duration, erf ${ }^{-1}$ is the inverse of error function, $c_{d}$ is chloride concentration at which the color changes, and $c_{0}$ is the chloride concentration in the catholyte solution.

\section{Test Results and Discussion}

3.1. Fresh Concrete Properties and Compressive Strength. It was observed from the test results that slumps and air contents of all of the concrete mixtures satisfied the target values, respectively, although there is a slight difference according to mix proportions as shown in Table 3.

Figure 2 shows compressive strengths with age of concrete containing GGBFS which was 20,40 , and $60 \%$ by mass of the unit binder content, respectively. It was on the whole revealed that compressive strengths of concrete containing GGBFS were smaller than those of OPC concrete at 28 days but were larger after 91 days, even though there is a slight difference according to W/B. Figure 3 shows compressive strengths with age of concrete containing FA which was 10 , 20 , and $30 \%$ by mass of the unit binder content, respectively. It was found that compressive strengths of concrete containing FA were smaller than those of OPC concrete up to 91 days but were larger after 182 days. It is noted that the supplementary materials such as GGBFS and FA significantly influence the compressive strength of concrete with ages.

3.2. Diffusion Coefficient for Chloride Ions. Table 4 shows the diffusion coefficients for chloride ions in concrete at $28,91,182,273$, and 365 days as an average value of three specimens. The GGBFS concrete yielded a lower diffusion 


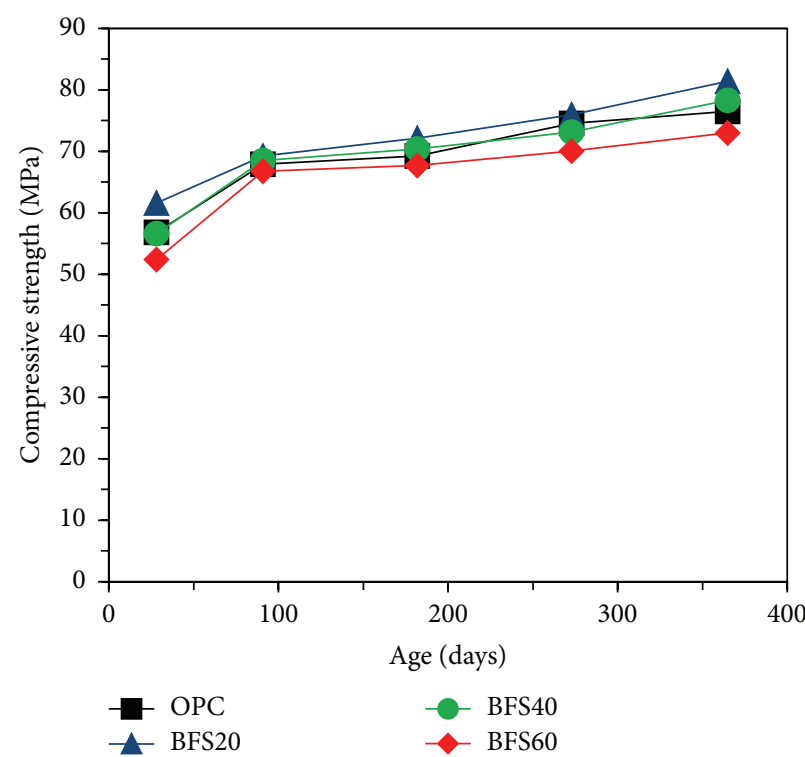

(a) $\mathrm{W} / \mathrm{B}=35 \%$

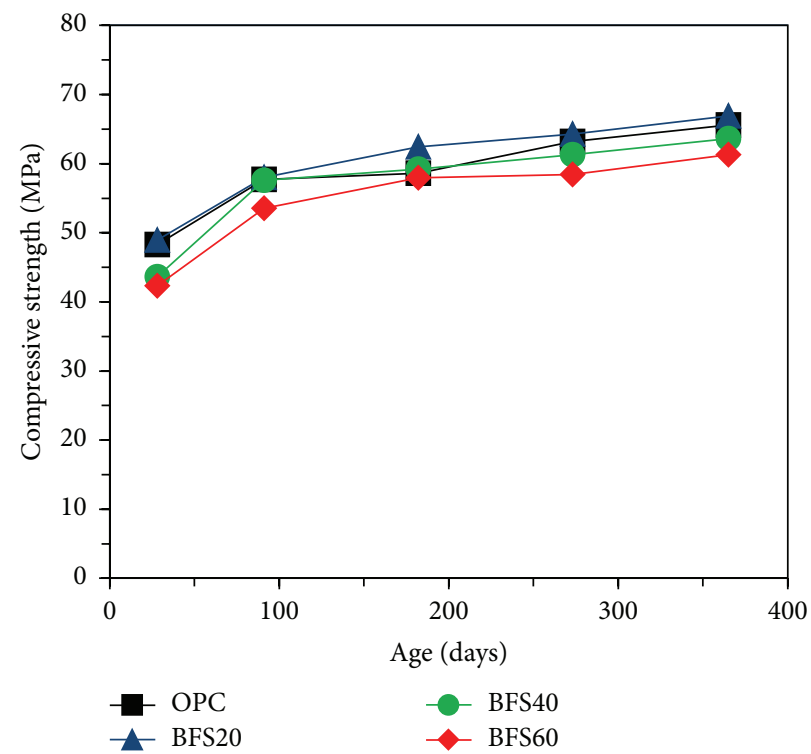

(b) $\mathrm{W} / \mathrm{B}=45 \%$

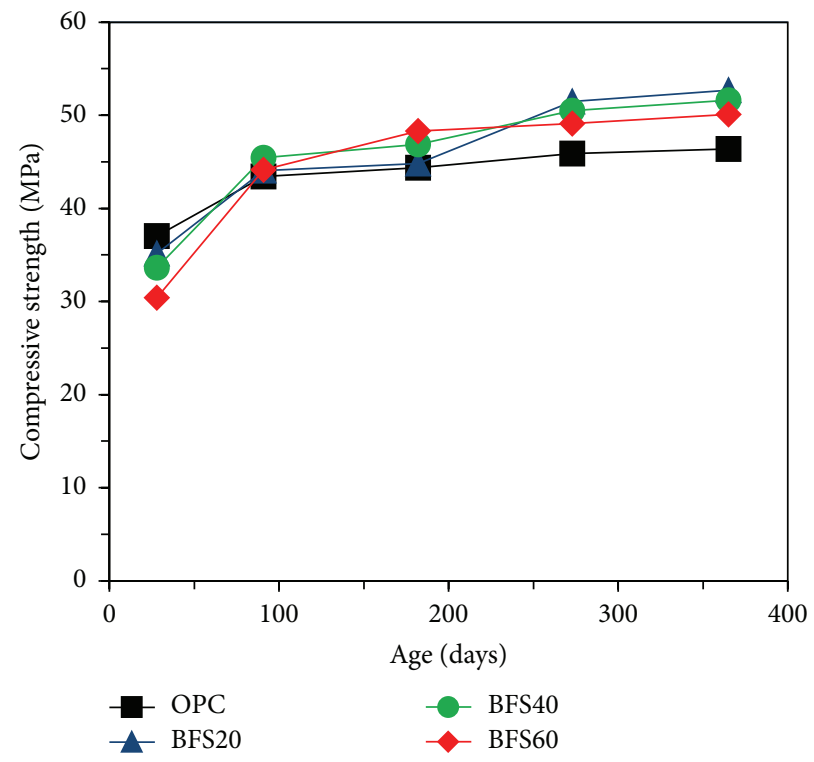

(c) $\mathrm{W} / \mathrm{B}=55 \%$

FIGURE 2: Compressive strength of GGBFS concrete with W/B.

coefficient for chloride ions than OPC concrete regardless of the $\mathrm{W} / \mathrm{B}$ and ages, and the diffusion coefficient decreased as the replacement ratio of GGBFS increased. GGBFS concrete showed improved resistance against chloride ions penetration throughout the ages.

Although the diffusion coefficient for chloride ions of FA concrete at 28 days increased as the FA replacement ratio increased, the coefficients decreased from 91 days. Such phenomenon seems to be caused by the finer microstructure due to the pozzolanic reaction activated at later age. The resistance against chloride ions penetration at 28 days for FA concrete with relatively large W/Bs of 45 and $55 \%$ was generally worse than that of OPC concrete, but the resistance improved after 91 days.

\section{Prediction of Diffusion Decay Coefficient for Chloride Ions}

4.1. Time-Dependent Diffusion Coefficient. This study employed (2) which represents the change in a diffusion coefficient in the power equation form with respect to the diffusion coefficient of a certain age. Hence,

$$
D(t)=D_{\text {ref }}\left(\frac{t_{\text {ref }}}{t}\right)^{m},
$$

where $D(t)$ is the diffusion coefficient for chloride ions at age $t, D_{\text {ref }}$ is the diffusion coefficient for chloride ions at some reference age $t_{\text {ref }}$ (28 days), and $m$ is the diffusion decay coefficient for chloride ions. The coefficient, $m$, which 


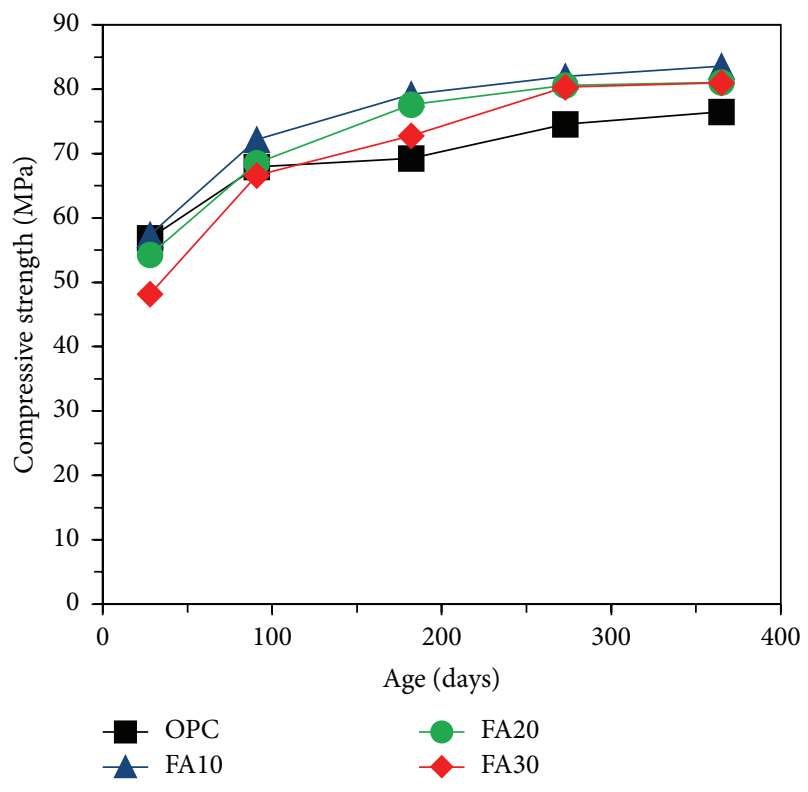

(a) $\mathrm{W} / \mathrm{B}=35 \%$

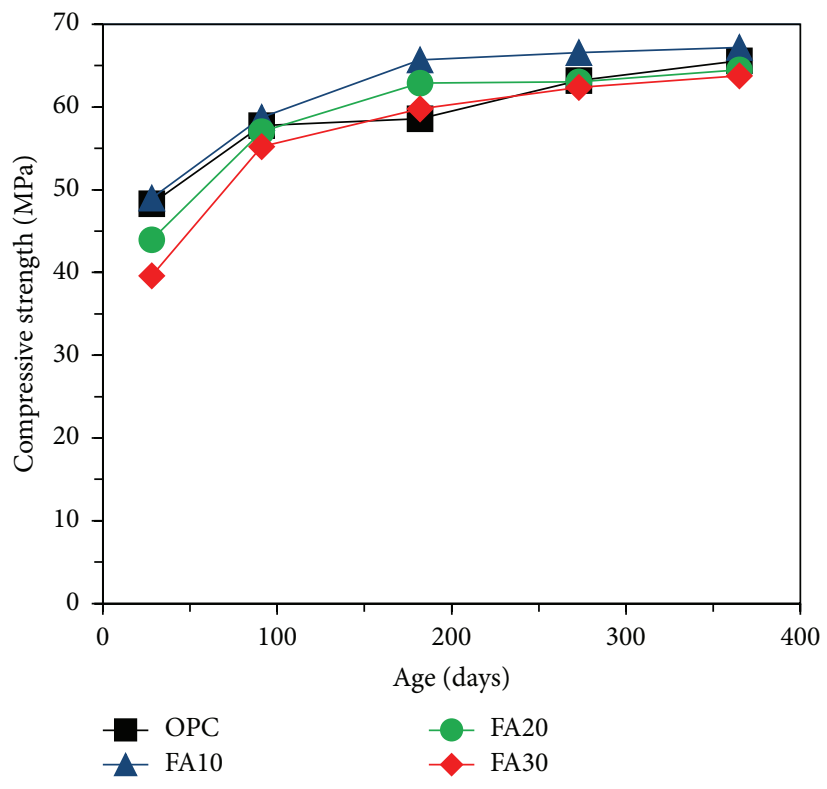

(b) $\mathrm{W} / \mathrm{B}=45 \%$

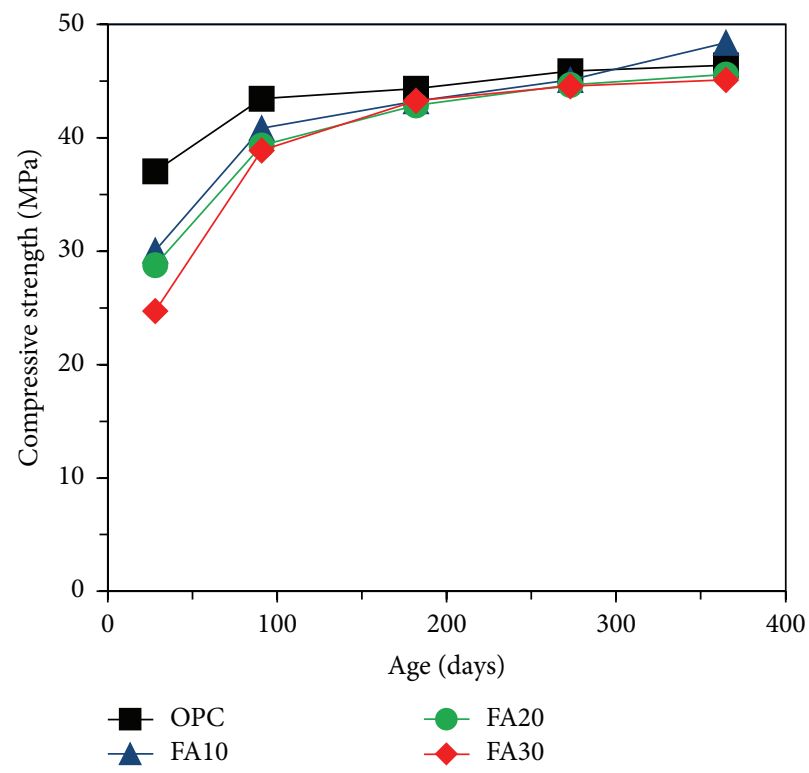

(c) $\mathrm{W} / \mathrm{B}=55 \%$

FIGURE 3: Compressive strength of FA concrete with W/B.

represents the diffusion coefficient that varies with time, is often called the time-dependent index of diffusion coefficient for chloride ions.

Table 5 shows the diffusion decay coefficients for chloride ions in concrete using OPC and BBC with W/Bs of 35, 45 , and $55 \%$. The reference age is 28 days. The diffusion decay coefficients for chloride ions of OPC concrete are in the range of $0.16 \sim 0.34$, and the lower the $\mathrm{W} / \mathrm{B}$, the larger the diffusion decay coefficient. The diffusion decay coefficients for concrete using GGBFS with $20 \%, 40 \%$, and $60 \%$ are in the ranges of $0.32 \sim 0.36,0.41 \sim 0.52$, and
$0.45 \sim 0.70$, respectively. The diffusion decay coefficient on the whole increases as W/B and the GGBFS replacement ratio increase.

FA concrete has a high diffusion coefficient at early ages and the coefficient clearly decreases with increasing age. In addition, a small $\mathrm{W} / \mathrm{B}$ resulted in a large diffusion decay coefficient for FA concrete at 28 days. The diffusion decay coefficients of concrete containing FA with $10 \%, 20 \%$, and $30 \%$ were in the ranges of $0.51 \sim 0.63,0.77 \sim 0.96$, and 0.99 , respectively, and the coefficient increases with the replacement ratio of FA. 
TABLE 4: Average diffusion coefficients for chloride ions of concrete.

\begin{tabular}{|c|c|c|c|c|c|c|}
\hline \multirow{2}{*}{$\mathrm{W} / \mathrm{B}(\%)$} & \multirow{2}{*}{ Cement type } & \multicolumn{4}{|c|}{ Diffusion coefficient for chloride ions $\left(\times 10^{-12}, \mathrm{~m}^{2} / \mathrm{s}\right)$} & \multirow[b]{2}{*}{365 day } \\
\hline & & 28 days & 91 days & 182 days & 273 days & \\
\hline \multirow{7}{*}{35} & OPC & 11.64 & 6.85 & 5.99 & 5.25 & 4.99 \\
\hline & GGBFS20 & 6.27 & 4.19 & 3.03 & 2.86 & 2.42 \\
\hline & GGBFS40 & 4.43 & 2.23 & 2.19 & 1.66 & 1.53 \\
\hline & GGBFS60 & 3.54 & 1.99 & 1.56 & 1.38 & 1.02 \\
\hline & FA10 & 8.70 & 3.64 & 2.69 & 2.33 & 1.91 \\
\hline & FA20 & 9.32 & 2.30 & 1.60 & 1.49 & 1.40 \\
\hline & FA30 & 10.08 & 1.98 & 1.53 & 1.34 & 1.29 \\
\hline \multirow{7}{*}{45} & OPC & 17.27 & 13.51 & 11.05 & 10.17 & 9.62 \\
\hline & GGBFS20 & 9.18 & 6.25 & 5.03 & 4.39 & 4.19 \\
\hline & GGBFS40 & 8.52 & 4.26 & 3.68 & 2.64 & 2.27 \\
\hline & GGBFS60 & 5.80 & 2.40 & 2.19 & 1.89 & 1.54 \\
\hline & FA10 & 12.69 & 6.92 & 5.20 & 3.68 & 3.42 \\
\hline & FA20 & 17.55 & 6.02 & 3.42 & 2.95 & 2.71 \\
\hline & FA30 & 19.82 & 4.92 & 2.34 & 2.05 & 1.61 \\
\hline \multirow{7}{*}{55} & OPC & 24.51 & 19.89 & 17.55 & 17.11 & 16.84 \\
\hline & GGBFS20 & 16.53 & 9.29 & 8.88 & 8.61 & 8.47 \\
\hline & GGBFS40 & 11.06 & 4.76 & 4.02 & 3.90 & 3.49 \\
\hline & GGBFS60 & 8.38 & 2.88 & 2.47 & 2.00 & 1.75 \\
\hline & FA10 & 36.93 & 15.99 & 12.18 & 11.45 & 10.68 \\
\hline & FA20 & 38.27 & 12.38 & 9.60 & 8.02 & 7.13 \\
\hline & FA30 & 42.04 & 11.16 & 5.22 & 4.75 & 4.26 \\
\hline
\end{tabular}

TABLE 5: Diffusion decay coefficients for chloride ions for concrete.

\begin{tabular}{cccc}
\hline W/B (\%) & Cement type & $m$ & $\Delta$ \\
\hline \multirow{4}{*}{35} & OPC & 0.34 & - \\
& GGBFS20 & 0.36 & 0.02 \\
& GGBFS40 & 0.43 & 0.09 \\
& GGBFS60 & 0.45 & 0.11 \\
& FA10 & 0.63 & 0.29 \\
& FA20 & 0.96 & 0.62 \\
& FA30 & 0.99 & 0.65 \\
\hline \multirow{4}{*}{45} & OPC & 0.23 & - \\
& GGBFS20 & 0.32 & 0.09 \\
& GGBFS40 & 0.41 & 0.18 \\
& GGBFS60 & 0.56 & 0.33 \\
& FA10 & 0.52 & 0.29 \\
& FA20 & 0.83 & 0.60 \\
& FA30 & 0.99 & 0.76 \\
\hline & OPC & 0.16 & - \\
& GGBFS20 & 0.32 & 0.16 \\
& GGBFS40 & 0.52 & 0.36 \\
& GGBFS60 & 0.70 & 0.54 \\
& FA10 & 0.51 & 0.35 \\
& FA20 & 0.77 & 0.61 \\
& FA30 & 0.99 & 0.83 \\
\hline & & &
\end{tabular}

4.2. Prediction of Diffusion Decay Coefficient. A regression analysis on the diffusion decay coefficient for chloride ions given in Table 5 was conducted using a commercial statistical analysis program. $\mathrm{W} / \mathrm{B}$ and the replacement ratio of admixture were considered as variables. A form given by (3) was proposed for the prediction of the diffusion decay coefficient of concrete using OPC and binary blended cement. Hence,

$$
m=m_{\mathrm{OPC}}+\Delta_{m}
$$

where $m_{\mathrm{OPC}}$ is the diffusion decay coefficient of OPC and $\Delta_{m}$ is the increment change of diffusion decay coefficient according to the replacement ratio of admixture. The diffusion decay coefficient for GGBFS concrete or FA concrete was expressed as the sum of the diffusion decay coefficient of OPC $\left(m_{\mathrm{OPC}}\right)$ and the increment due to the use of GGBFS or FA $\left(\Delta_{m}\right)$.

As shown in Table $5, m_{\mathrm{OPC}}$ is strongly influenced by W/B and an increment change of GGBFS concrete $\left(\Delta_{m \text { (GGBFS })}\right)$ was proportional to both the replacement level and $\mathrm{W} / \mathrm{B}$, while an increment change of FA concrete $\left(\Delta_{m(\mathrm{FA})}\right)$ was proportional to the replacement level mainly.

Thus, an increment change of mineral admixtures, $\Delta_{m}$, can be expressed as a function of both $\mathrm{W} / \mathrm{B}$ and the 




Figure 4: Comparison of diffusion coefficient measurements and predictions by empirical formula (OPC).

TABLE 6: Coefficients of empirical formula for OPC and BBC concrete.

\begin{tabular}{lccccccccc}
\hline Type & $\alpha$ & $\beta$ & $\gamma$ & $a$ & $b$ & $c$ & $d$ & $e$ & $R^{2}$ \\
\hline OPC & 0.06 & - & - & -1.66 & - & - & - & - & 0.99 \\
GGBFS & - & 4.24 & - & - & 1.12 & 3.16 & - & - & 0.98 \\
FA & - & - & 1.25 & - & - & - & 0.75 & 0.33 & 0.95 \\
\hline
\end{tabular}

replacement ratio of GGBFS or FA. Empirical formulas for the prediction of $m_{\mathrm{GGBFS}}$ and $m_{\mathrm{FA}}$ are given by

$$
\begin{aligned}
m_{\mathrm{OPC}} & =\alpha(\mathrm{W} / \mathrm{B})^{a}, \\
m_{\mathrm{GGBFS}} & =\alpha(\mathrm{W} / \mathrm{B})^{a}+\beta\left(\frac{\mathrm{GGBFS}(\%)}{70}\right)^{b}(\mathrm{~W} / \mathrm{B})^{c}, \\
m_{\mathrm{FA}} & =\alpha(\mathrm{W} / \mathrm{B})^{a}+\gamma\left(\frac{\mathrm{FA}(\%)}{40}\right)^{d}(\mathrm{~W} / \mathrm{B})^{e},
\end{aligned}
$$

where $\mathrm{W} / \mathrm{B}$ is the water-binder ratio, GGBFS (\%) is the replacement ratio of GGBFS (\%), FA (\%) is the replacement ratio of FA (\%), and $\alpha, \beta, \gamma, a, b, c, d$, and $e$ are coefficients. The empirical formulas given in (4a)-(4c) are valid up to the replacement level of $70 \%$ for GGBFS or 30\% for FA and $m$ cannot exceed 0.99. Regression analysis results are shown in Table 6.

Table 7 shows the relationship between the diffusion decay coefficients as determined by the empirical formulas given in Table 6 for the OPC and BBC concrete. It was found that errors of $m$ ranged from $0 \%$ to $9.6 \%$.

\begin{tabular}{|c|c|c|c|c|}
\hline $\begin{array}{l}\mathrm{W} / \mathrm{B} \\
(\%)\end{array}$ & Cement type & $\begin{array}{c}\text { Measurement } \\
\text { (1) }\end{array}$ & $\begin{array}{l}\text { Empirical } \\
\text { formula } \\
(2)\end{array}$ & $\begin{array}{c}\text { Error } \\
\{(2)-(1)\} /(1) \\
(\%)\end{array}$ \\
\hline \multirow{7}{*}{35} & OPC & 0.34 & 0.34 & 0.0 \\
\hline & GGBFS20 & 0.36 & 0.38 & 5.6 \\
\hline & GGBFS40 & 0.43 & 0.42 & -2.3 \\
\hline & GGBFS60 & 0.45 & 0.47 & 4.4 \\
\hline & FA10 & 0.63 & 0.66 & 4.8 \\
\hline & FA20 & 0.96 & 0.87 & -9.4 \\
\hline & FA30 & 0.99 & 0.99 & 0.0 \\
\hline \multirow{7}{*}{45} & OPC & 0.23 & 0.23 & 0.0 \\
\hline & GGBFS20 & 0.32 & 0.31 & -3.1 \\
\hline & GGBFS40 & 0.41 & 0.41 & 0.0 \\
\hline & GGBFS60 & 0.56 & 0.51 & -8.9 \\
\hline & FA10 & 0.52 & 0.57 & 9.6 \\
\hline & FA20 & 0.83 & 0.80 & -3.6 \\
\hline & FA30 & 0.99 & 0.99 & 0.0 \\
\hline \multirow{7}{*}{55} & OPC & 0.16 & 0.16 & 0.0 \\
\hline & GGBFS20 & 0.32 & 0.32 & 0.0 \\
\hline & GGBFS40 & 0.52 & 0.50 & -3.8 \\
\hline & GGBFS60 & 0.70 & 0.70 & 0.0 \\
\hline & FA10 & 0.51 & 0.52 & 2.0 \\
\hline & FA20 & 0.77 & 0.77 & 0.0 \\
\hline & FA30 & 0.99 & 0.99 & 0.0 \\
\hline
\end{tabular}

TABle 7: Diffusion decay coefficients of concrete by regression analysis.

TABLE 8: Input data used for the verification $(\mathrm{W} / \mathrm{B}=45 \%)$.

\begin{tabular}{lccc}
\hline Type & $D\left(\times 10^{-12}, \mathrm{~m}^{2} / \mathrm{s}\right)$ & \multicolumn{2}{c}{$m$} \\
& & Empirical formula & Life-365 model \\
\hline OPC & 17.27 & 0.23 & 0.20 \\
GGBFS60 & 5.80 & 0.51 & 0.54 \\
FA10 & 12.69 & 0.57 & 0.28 \\
\hline
\end{tabular}

Figures 4-6 represent the relationship between the measured diffusion coefficient determined by the migration test and the predicted diffusion coefficient obtained by the empirical formulas for the OPC, GGBFS, or FA concrete. There is generally a good correlation between the predictions and the measurements.

Figure 7 shows the diffusion coefficient for chloride ions at $28,91,182,273$, and 365 days of OPC, GGBFS $60 \%$, and FA $10 \%$ concrete, determined by substituting the diffusion decay coefficient for chloride ions for (2), based on Table 8. It was revealed that the predictions obtained by $(4 \mathrm{a})-(4 \mathrm{~b})$ coincided relatively well with those predicted by Life- 365 model [2]. On the other hand, since the diffusion coefficients of FA concrete 


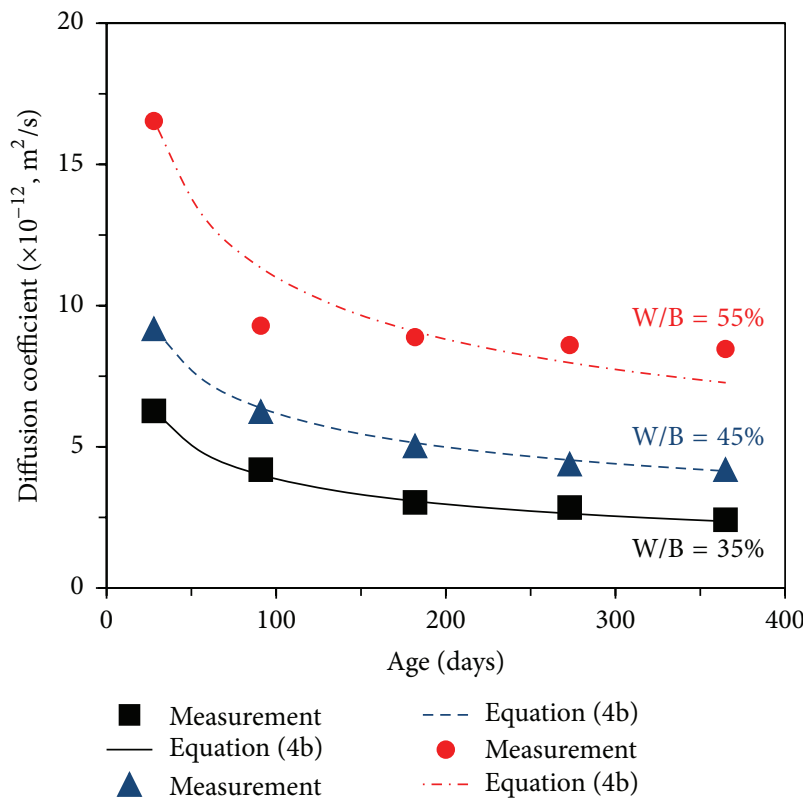

(a) GGBFS20

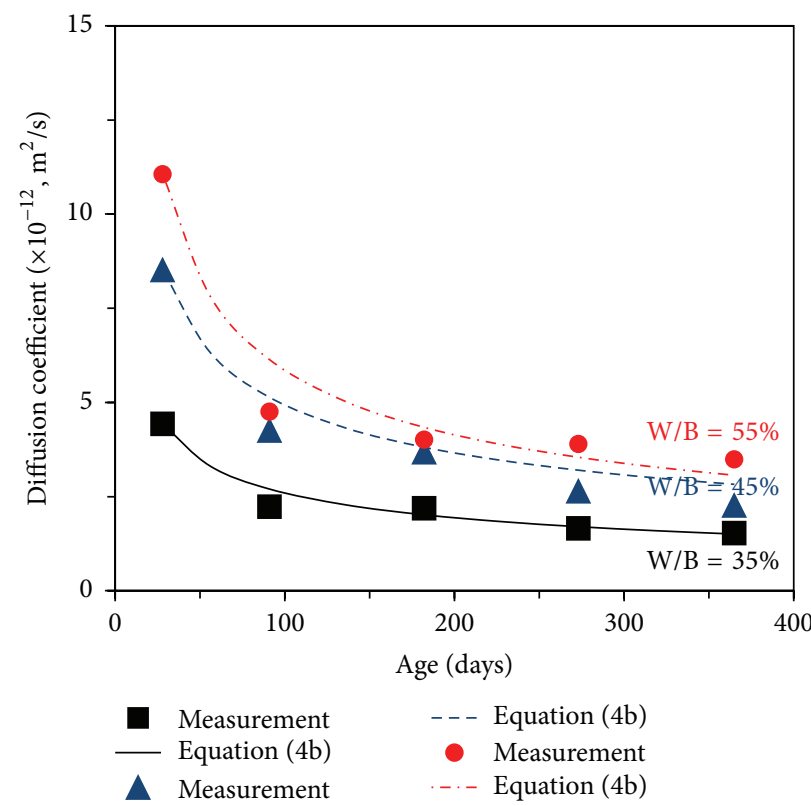

(b) GGBFS40

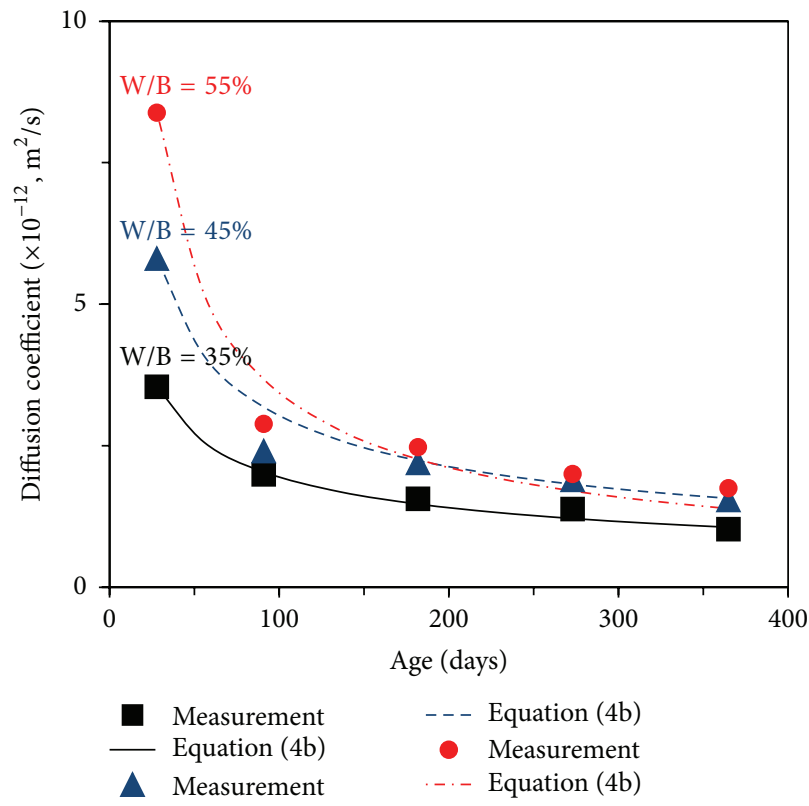

(c) GGBFS60

FIGURE 5: Comparison of diffusion coefficient measurements and predictions by empirical formula (GGBFS).

measured at early ages are much higher than those of ordinary FA concrete, the $m$ value by (4c) is larger than that by Life- 365 model.

\section{Conclusions}

The following conclusions were drawn from the experimental study of the diffusion decay coefficient for chloride ions for concrete using binary blended cement:
(1) The resistance against chloride ions penetration of concrete containing GGBFS was superior to that of OPC concrete regardless of the $\mathrm{W} / \mathrm{B}$ and age. In addition, increasing GGBFS replacement ratio improved resistance against chloride ions penetration. The resistance against chloride ions penetration of concrete containing FA decreased with increasing FA replacement ratio during early age; however, the resistance against chloride ions penetration after 


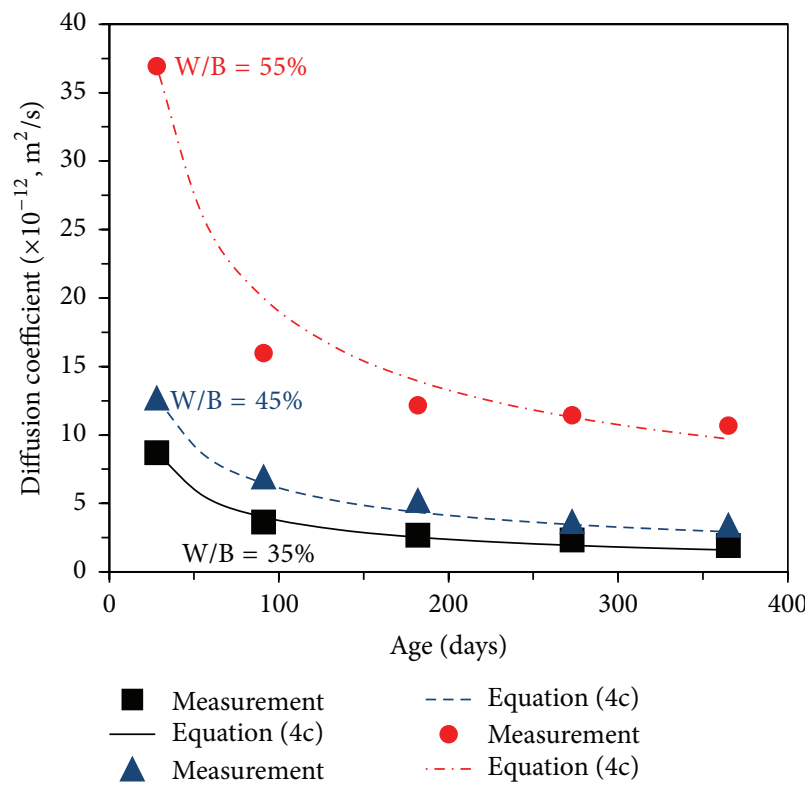

(a) FA10



(b) FA20



(c) FA30

FIGURE 6: Comparison of diffusion coefficient measurements and predictions by empirical formula (FA).

91 days improved with increasing FA replacement ratio.

(2) The diffusion decay coefficient for chloride ions for $\mathrm{OPC}$ concrete is strongly influenced by $\mathrm{W} / \mathrm{B}$, and the lower the $\mathrm{W} / \mathrm{B}$, the larger the coefficient. For BBC concrete, the diffusion decay coefficients for chloride ions for GGBFS concrete on the whole increase as $\mathrm{W} / \mathrm{B}$ and the GGBFS replacement ratio increase. On the contrary, the coefficients for FA concrete increase with decreasing W/B and increasing FA replacement ratio.

(3) Empirical formulas were proposed to predict the diffusion decay coefficient for chloride ions for OPC and $\mathrm{BBC}$ concrete, considering both $\mathrm{W} / \mathrm{B}$ and the replacement ratio of GGBFS or FA. It is found that the diffusion decay coefficient values predicted by the empirical formulas agreed well with those obtained by Life-365 model for OPC and GGBFS concrete with $\mathrm{W} / \mathrm{B}$ of $45 \%$. The empirical formula would be useful to 


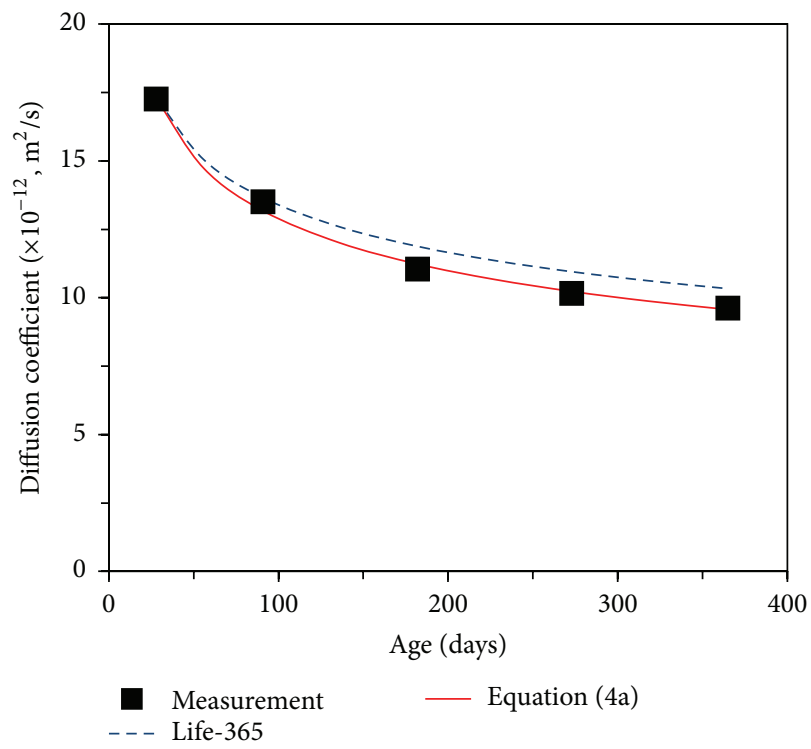

(a) OPC

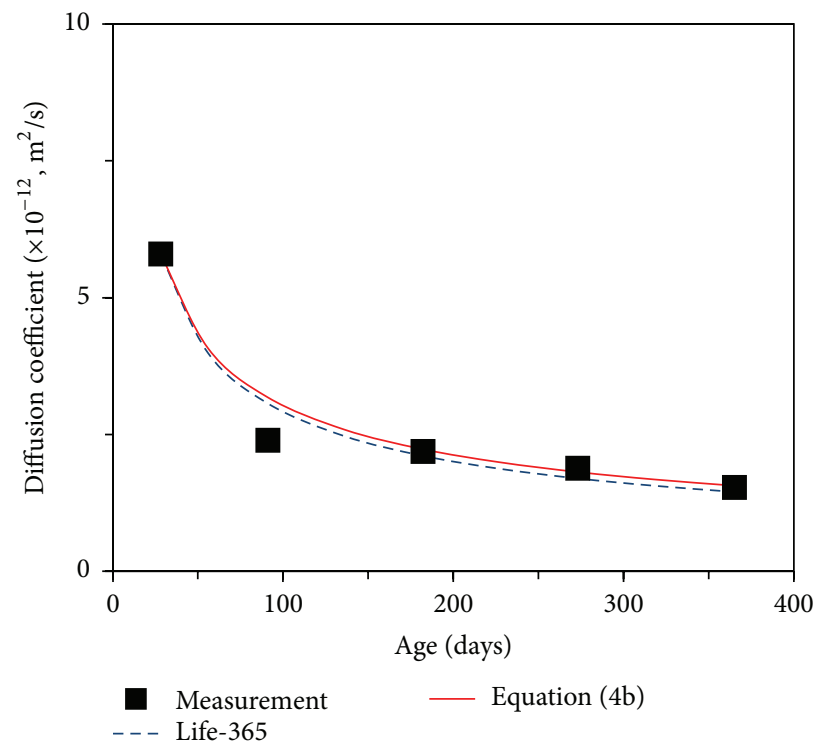

(b) GGBFS60

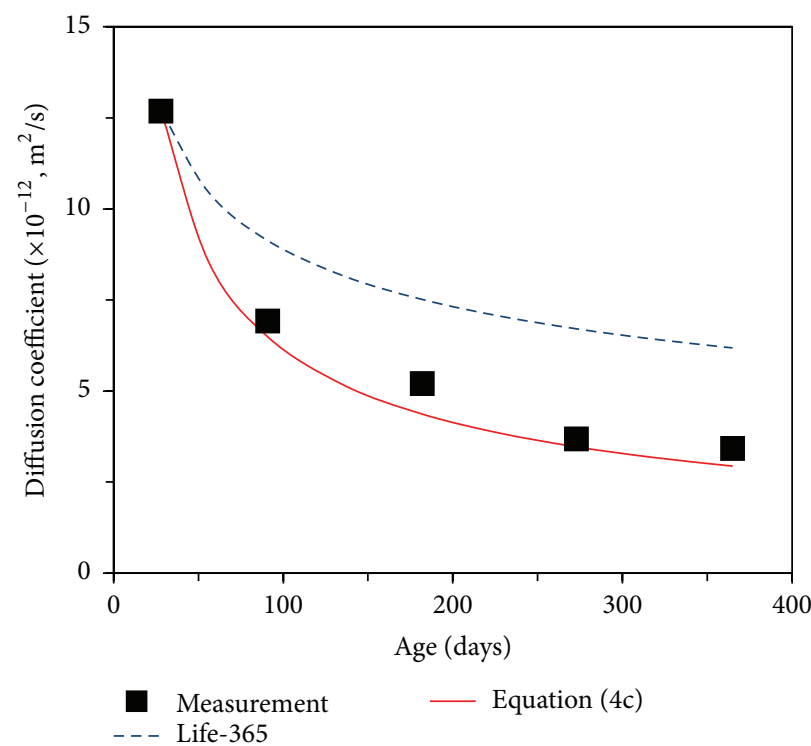

(c) FA10

FiguRE 7: Comparison of diffusion coefficient measurements and predictions by empirical formula and Life-365 model $(\mathrm{W} / \mathrm{B}=45 \%)$.

evaluate the service life of concrete structures exposed to chloride attack.

\section{Competing Interests}

The authors declare that there are no competing interests regarding the publication of this paper.

\section{Acknowledgments}

This work was supported by the Nuclear Research \& Development of the Korea Institute of Energy Technology Evaluation and Planning (KETEP) grant funded by the Korean government's Ministry of Knowledge Economy.

\section{References}

[1] DuraCrete, "Probabilistic performance based durability design of concrete structures," Final Technical Report Document BE95-1347/R17, European Brite-EuramIII, CUR, Gouda, The Netherlands, 2000.

[2] E. C. Bentzand and M. D. A. Thomas, Computer Program for Predicting the Service Life and Life-Cycle Costs of Reinforced Concrete Exposed to Chlorides, Life-365 Manual, SFA, 2002.

[3] International Federation for Structural Concrete (fib), "Model code for service life design (SLD)," Fib Bulletin 34, 2006.

[4] C. Gehlen, "Durability design according to the new model code for service life design," in Proceedings of the Fifth International Conference on Concrete under Severe Conditions-Environment and Loading, F. Toutlemonde, K. Sakai, O. E. Gjørv, and N. 
Banthia, Eds., vol. 1, pp. 35-50, Laboratoire Central des Ponts et Chaussées, Paris, France, 2007.

[5] O. E. Gjørv, Durability Design of Concrete Structures in Severe Environments, Taylor \& Francis, London, UK, 2009.

[6] O. E. Gjørv, "Service life and sustainability of important concrete infrastuctures," in Proceedings of the Second International Conference on Sustainable Construction Materials and Technologies, pp. 239-249, 2010.

[7] O. E. Gjørv, "Durability design and quality assurance of major concrete infrastructure," Advances in concrete construction, vol. 1, no. 1, pp. 45-63, 2013.

[8] O. E. Gjørv, "Durability of concrete structures," Arabian Journal for Science and Engineering, vol. 36, no. 2, pp. 151-172, 2011.

[9] C. Andrade, M. Prieto, P. Tanner, F. Tavares, and R. d'Andrea, "Testing and modelling chloride penetration into concrete," Construction and Building Materials, vol. 39, pp. 9-18, 2013.

[10] A. Petcherdchoo, "Time dependent models of apparent diffusion coefficient and surface chloride for chloride transport in fly ash concrete," Construction and Building Materials, vol. 38, pp. 497-507, 2013.

[11] M. Nokken, A. Boddy, R. D. Hooton, and M. D. A. Thomas, "Time dependent diffusion in concrete-three laboratory studies," Cement and Concrete Research, vol. 36, no. 1, pp. 200-207, 2006.

[12] X. Shi, N. Xie, K. Fortune, and J. Gong, "Durability of steel reinforced concrete in chloride environments: an overview," Construction and Building Materials, vol. 30, pp. 125-138, 2012.

[13] W.-M. Zhang, H.-J. Ba, and S.-J. Chen, "Effect of fly ash and repeated loading on diffusion coefficient in chloride migration test," Construction and Building Materials, vol. 25, no. 5, pp. 2269-2274, 2011.

[14] K. Audenaert, Q. Yuan, and G. De Schutter, "On the time dependency of the chloride migration coefficient in concrete," Construction and Building Materials, vol. 24, no. 3, pp. 396-402, 2010.

[15] P. Spiesz and H. J. H. Brouwers, "The apparent and effective chloride migration coefficients obtained in migration tests," Cement and Concrete Research, vol. 48, pp. 116-127, 2013.

[16] Nordtest, "Concrete, mortar and cement based repair materials, chloride migration coefficient from non-steady-state migration experiments," NT BUILD 492, Nordtest, 1999.

[17] E. J. Yingqin and P. E. NurYazdani, "Substitution of fly ash, slag, and chemical admixtures in concrete mix designs," Journal of Materials in Civil Engineering, vol. 15, no. 6, pp. 602-608, 2003.

[18] R. Bleszynski, R. D. Hooton, M. D. A. Thomas, and C. A. Rogers, "Durability of ternary blended concrete with silica fume and blast-furnace slag: laboratory and outdoor exposure site studies," ACI Materials Journal, vol. 99, no. 5, pp. 499-508, 2002. 

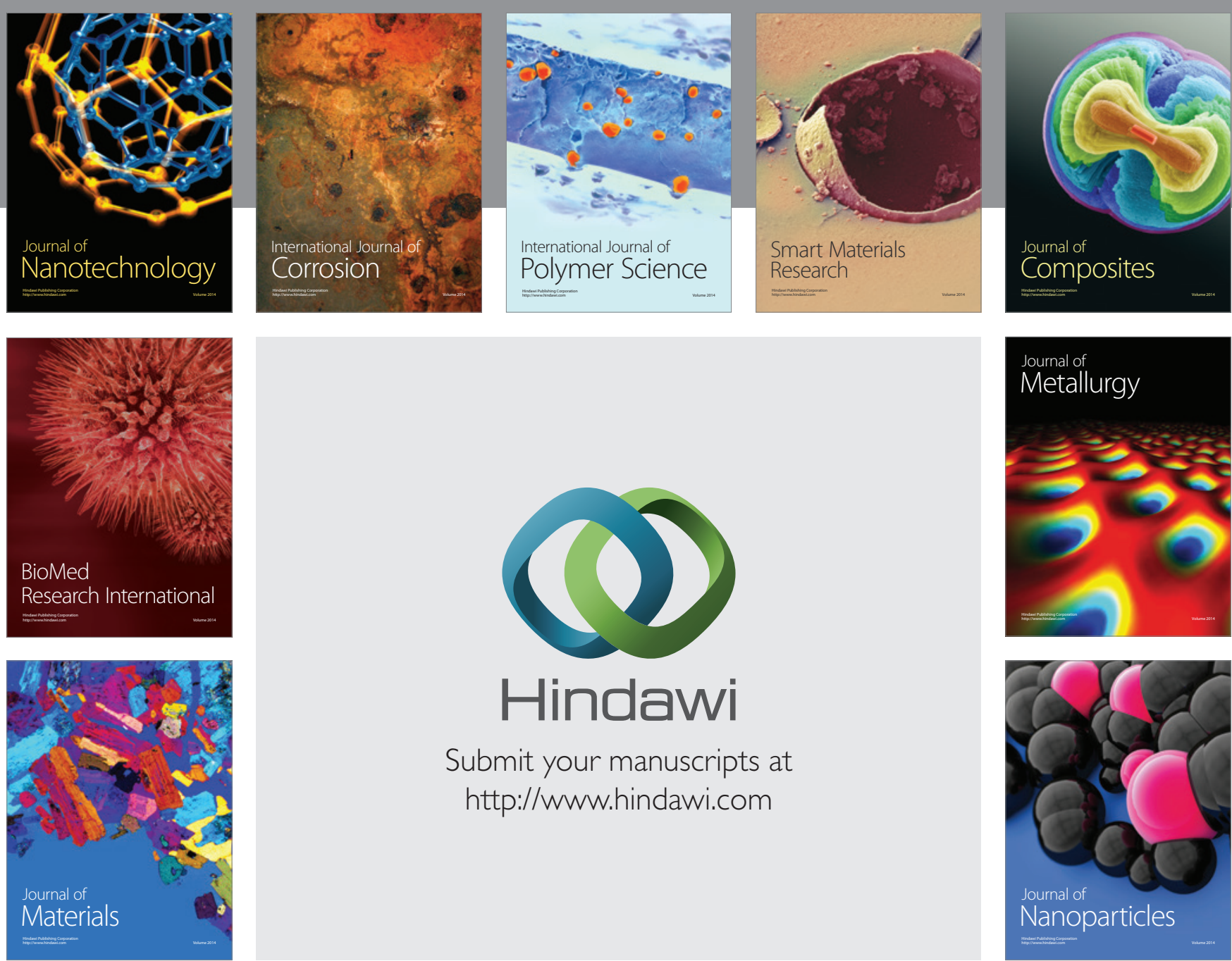

\section{Hindawi}

Submit your manuscripts at

http://www.hindawi.com

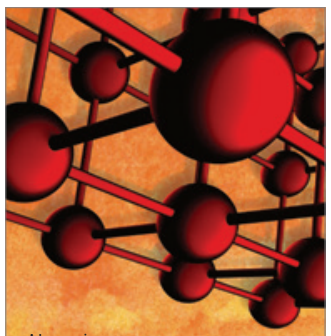

Materials Science and Engineering

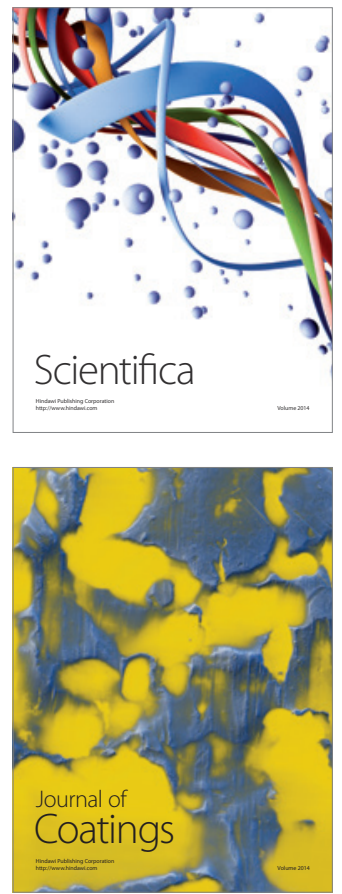
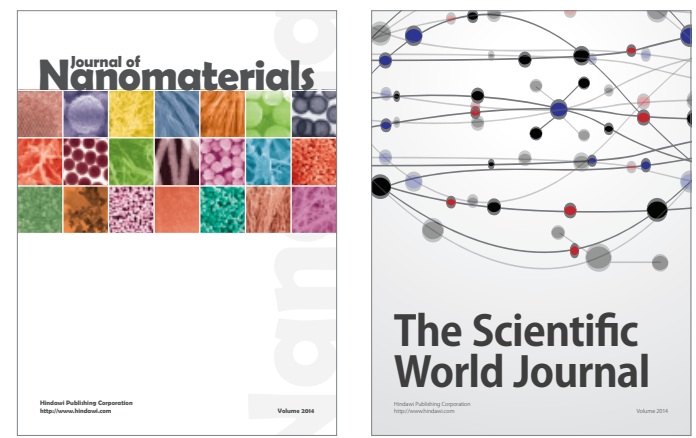

The Scientific World Journal
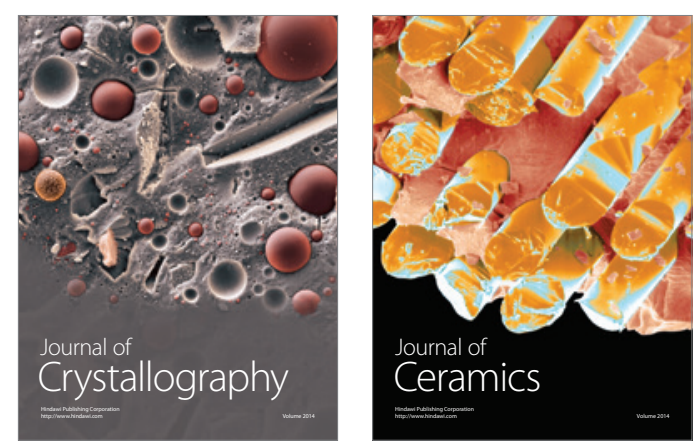
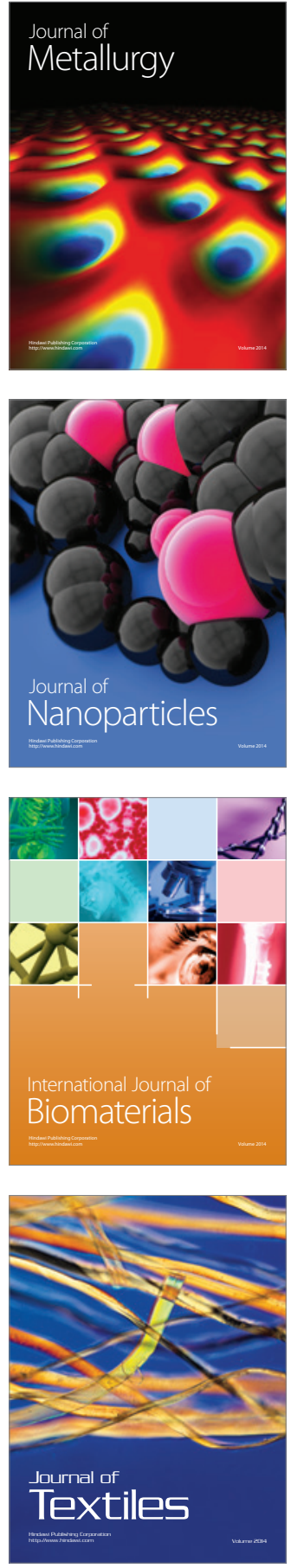